\title{
EFFECTIVENESS OF GLUTEAL MUSCLE STRENGTHENING ON FLAT FOOT
}

\author{
POOJA MULCHANDANI, TRUPTI WARUDE, AMRUTKUVAR PAWAR
}

Department of Musculoskeletal Sciences, Krishna College of Physiotherapy, KIMSDU, Karad, Maharashtra, India. Email: poojamulchandani0709@gmail.com

Received: 14 February 2016, Revised and Accepted: 17 March 2017

ABSTRACT

Objectives: To compare the effect of gluteal muscle strengthening along with conventional exercises versus conventional exercises alone on flat foot.

Method: An experimental study conducted at Physiotherapy Department of Krishna Institute of Medical Sciences, Karad. A total of 52 subjects were equally divided into two groups using convenient sampling with random allocation (Groups A and B). Baseline treatment was given to both groups (intrinsic muscle strengthening). Group A was given intrinsic muscle strengthening alone while Group B was given gluteal muscle strengthening along with intrinsic muscle strengthening.

Result: Statistical analysis was performed using paired t-test and unpaired t-test. In pre-intervention there was no statistically significant difference seen with $\mathrm{p}$ values for the navicular drop was 0.3563 and for Ink test was 0.7342 . While on comparing the post-interventional values, the results between the two groups using paired t-test revealed that there was extremely significant difference seen with p-value for the navicular drop was $<0.0001$ and for Ink test was $<0.0001$.

Conclusion: From the study, it can be concluded that there was a significant effect of gluteal muscle strengthening on the flat foot

Keywords: Flat foot, Gluteal muscle strengthening, Intrinsic muscle strengthening, Navicular drop, Ink test.

(C) 2017 The Authors. Published by Innovare Academic Sciences Pvt Ltd. This is an open access article under the CC BY license (http://creativecommons. org/licenses/by/4. 0/) DOI: http://dx.doi.org/10.22159/ajpcr.2017.v10i6.17719

\section{INTRODUCTION}

Flat foot is the condition in which the medial longitudinal arch (MLA) becomes chronically or abnormally low [1]. Flat foot is divided into two: Spastic flat foot and flexible flat foot [2]. Flexible flat foot: Flexible pronated foot has a normal range of motion of the mid-tarsal joints and has a flattened MLA only on weight-bearing. When non-weight bearing or standing on their toes, the longitudinal arch is present. Rigid/spastic flat foot: Rigid flat foot has a limited mid-tarsal motion and continues to have a flattened arch when non-weight bearing.

If the foot becomes diseased or deformed, the foot adapts to perform its functions under the conditions of disease or deformity [3]. Within the sole is the lateral longitudinal arch, the MLA and the transverse arch [4]. The MLA is controlled with the assistance of the bone structures, ligaments, and the extrinsic, and intrinsic muscles of the foot [5]. The prevalence of flat foot in a population of 18-25 years old students was $11.25 \%[6]$.

Intrinsic muscle strengthening $[7,8]$ : The foot intrinsic muscles consist of several smaller muscles located on the bottom of the foot. Just as the core muscles around the spine are essential to stabilize and protect the spine, the foot intrinsic muscles must do the same for the many bones and joints of the foot. In fact, weak foot intrinsic muscles can cause a lower arch height and foot over-pronation. When the foot intrinsic muscles are weak and unable to support the foot properly, they must be strengthened. This can be done through a series of foot intrinsic exercises, which like other exercises can be progressed and made more challenging over a time to stimulate muscle adaptations in strength, control, and endurance.

Gluteal muscle strengthening: The gluteal muscles (maximus, medius, and minimus) stabilize the hip by counteracting gravity's hip adduction torque and maintain proper leg alignment by eccentrically controlling adduction and internal rotation of the thigh $[9,10]$. Re-activating the gluteal muscles will re-establish correct muscle recruitment patterns and enhance strength and performance.

\section{METHODS}

It was an experimental study conducted in the Physiotherapy Department of Krishna Institute of Medical Sciences. Ethical permission was obtained from Institutional Ethical Committee, KIMSDU, Karad. 52 subjects were equally divided into two groups using convenient sampling with random allocation. Baseline treatment was given to both groups which consisted of intrinsic muscle strengthening. Group A was given intrinsic muscle strengthening alone while Group B was given gluteal muscle strengthening along with intrinsic muscle strengthening. Subjects were selected according to inclusion and exclusion criteria. Written informed consent was taken, and the whole study was explained to them. A detailed musculoskeletal evaluation was done to screen the subjects. Inclusion criteria were as follows: (1) Navicular drop >10 mm, (2) plantar arch index >1.15, (3) age: 1825 years, (4) both genders, (5) unilateral flat foot, (6) subjects willing to participate, (7) positive tests out of: (i) Staheli's plantar arch index, (ii) Navicular drop test. Exclusion criteria were as follows: (1) Arthritis: Arthritis is wearing down of cartilage. The joints most commonly affected by arthritis are weight-bearing joints such as feet, knees, hips, and spine [11], (2) foot or ankle surgery, (3) Diabetes: Diabetes causes diabetic neuropathy which is a leading cause of significant morbidity. Double vision, drooping eyelids, weakness, and atrophy of muscles are symptoms of diabetic neuropathy which are slight at first sight but may flare up suddenly and affect specific nerves [12], (4) any foot abnormalities, (5) bilateral flat foot, (6) any present cuts on the lower extremity, and (7) uncooperative subjects.

Group A - treatment protocol will include intrinsic muscle strengthening (6 days/week for 4 weeks). 
Table 1: Comparison of pre- and post-navicular drop score within group

\begin{tabular}{lllllll}
\hline \multirow{2}{*}{ Group } & Pre-treatment & & \multicolumn{2}{l}{ Post-treatment } & p \\
\cline { 2 - 3 } & Mean \pm SD & Median & & Mean \pm SD & Median & \\
\hline A & $12.423 \pm 1.301$ & 12 & & $11.307 \pm 1.379$ & 11 & $<0.0001^{* *}$ \\
$\mathrm{~B}$ & $12.115 \pm 1.701$ & 12 & & $8.153 \pm 1.008$ & 8 & $<0.0001^{* *}$ \\
\hline$* *<0.0001$, extremely significant, SD: standard deviation &
\end{tabular}

Table 2: Comparison of pre-post navicular drop score between groups

\begin{tabular}{llllll}
\hline \multirow{2}{*}{ Group } & Pre-treatment & & & Post-treatment & \\
\cline { 2 - 3 } \cline { 5 - 6 } & Mean \pm SD & Median & & Mean \pm SD & Median \\
\hline $\mathrm{A}$ & $12.423 \pm 1.301$ & 12 & & $11.307 \pm 1.379$ & 11 \\
$\mathrm{~B}$ & $12.115 \pm 1.071$ & 12 & & $8.153 \pm 1.008$ & 8 \\
$\mathrm{p}$ & 0.3563 & & $<0.0001^{* *}$ & \\
\hline$* *<0.0001$, extremely significant, SD: standard deviation
\end{tabular}

Table 3: Comparison of pre- and post-ink test score within group

\begin{tabular}{lllllll}
\hline \multirow{2}{*}{ Group } & \multicolumn{2}{l}{ Pre-treatment } & & \multicolumn{2}{l}{ Post-treatment } & p \\
\cline { 2 - 3 } & Mean \pm SD & Median & & Mean \pm SD & Median & \\
\hline A & $1.287 \pm 0.12$ & 1.24 & & $0.970 \pm 0.80$ & 1.00 & $<0.0001^{* *}$ \\
$\mathrm{~B}$ & $1.277 \pm 0.08$ & 1.26 & & $0.762 \pm 0.07$ & 0.77 & $<0.0001^{* *}$ \\
\hline$* *<0.0001$, extremely significant, SD: standard deviation &
\end{tabular}

Table 4: Comparison of pre-post Ink test score between groups

\begin{tabular}{llllll}
\hline \multirow{2}{*}{ Group } & \multicolumn{2}{l}{ Pre-treatment } & & \multicolumn{2}{l}{ Post-treatment } \\
\cline { 2 - 3 } \cline { 5 - 6 } & Mean \pm SD & Median & & Mean \pm SD & Median \\
\hline $\mathrm{A}$ & $1.287 \pm 0.125$ & 1.245 & & $0.970 \pm 0.080$ & 1.00 \\
$\mathrm{~B}$ & $1.277 \pm 0.080$ & 1.265 & & $0.762 \pm 0.074$ & 0.77 \\
$\mathrm{p}$ & 0.7342 & & & $<0.0001^{* *}$ & \\
\hline$* *<0.0001$, extremely significant, SD: standard deviation
\end{tabular}

Group B - treatment protocol will include gluteal muscle strengthening along with intrinsic muscle strengthening ( 6 days/week for 4 weeks).

\section{Intrinsic muscle strengthening exercises}

- Short foot exercise (10 seconds hold, repeat 5 times, 2 sets).

- Heel raise (10 seconds hold, repeat 15 times, 2 sets).

- Toe curls (no hold, repeat 10 times, 2 sets).

\section{Gluteal muscle strengthening exercises}

- Clamshell (10 seconds hold, repeat 10 times, 2 sets)

- $\quad$ Side lying hip abduction (10 seconds hold, repeat 15 times, 2 sets).

- $\quad$ Single limb squat (no hold, repeat 5 times, 2 sets).

- Quadruped exercise (no hold, repeat 10 times, 2 sets).

\section{Outcome measure}

Navicular drop test - intragroup comparison (within group) using paired t-test.

In this study pre-interventional mean of the navicular drop score was $12.423 \pm 1.301$ in Group A and $12.115 \pm 1.701$ in Group B whereas the post-interventional mean of navicular drop score was $11.307 \pm 1.379$ in Group A and 8.153 \pm 1.008 in Group B. Intragroup analysis of navicular drop score revealed a statistical reduction in navicular drop postinterventional for both groups. This was done using paired t-test Group A ( $<<0.0001)$, Group B ( $<<0.0001)$.

Navicular drop test - intergroup (between groups) comparison using unpaired t-test.
In this study pre-interventional mean of the navicular drop score was $12.423 \pm 1.031$ in Group A and $12.115 \pm 1.071$ in Group B whereas post-interventional mean navicular drop score was $11.307 \pm 1.379$ in Group A and 8.153 \pm 1.008 in Group B. Intergroup analysis of navicular drop score was done by unpaired t-test. Pre-intervention analysis showed no significant difference between Groups A and B ( $p=0.3563)$. Post-intervention analysis showed an extremely significant difference between Groups A and B ( $\mathrm{p} \leq 0.0001)$.

Ink test: Intragroup comparison (within group) using paired t-test.

In this study pre-interventional mean of plantar arch index score was $1.287 \pm 0.12$ in Group A and $1.277 \pm 0.08$ in Group B, whereas the post-interventional mean of the plantar arch index was $0.970 \pm 0.80$ in Group A and $0.762 \pm 0.07$ in Group B, respectively. Intragroup analysis of plantar arch index revealed a statistical reduction in plantar arch index scores for both groups. This was done using paired t-test Group A $(\mathrm{p}<0.0001)$, Group B $(\mathrm{p}<0.0001)$.

Ink test - intergroup (between groups) comparison using unpaired t-test.

In this study pre-interventional means of Ink test score was $1.287 \pm 0.125$ in Group A and 1.27 \pm 0.080 in Group B whereas the post-interventional mean of Ink test score was $0.970 \pm 0.080$ in Group A and $0.762 \pm 0.074$ in Group B, respectively.

Intergroup analysis of Ink test score was performed using unpaired t-test. Post-intervention analysis showed an extremely significant difference between Groups A and B ( $p<0.0001)$.

\section{DISCUSSION}

The incidence of the flat foot has been reported to be $11.25 \%$ in a population of 18-25 years old students [6]. It has also been concluded that there is no correlation of body mass index (BMI) with arch index [6]. BMI is a simple index of weight-for-height that is commonly used to classify overweight and obesity, it is $\left(\mathrm{kg} / \mathrm{m}^{2}\right)$ [13] flat foot in otherwise healthy individuals is caused due to gluteal muscle (maximus, medius, and minimus) weakness. Gluteal muscle stabilizes the hip by counteracting gravity's hip adduction torque and maintain proper leg alignment by eccentrically controlling adduction and internal rotation of the thigh $[9,10]$. Gluteal muscle weakness internally rotates the hip joint inducing foot pronation [14].

Hence, the present clinical trial was conducted to find out the effect of gluteal muscle strengthening exercises along with intrinsic muscle strengthening exercises on the flat foot.

Since many studies set the criterion for the flat foot as $1.15 \mathrm{~cm}$ or more plantar arch index [15] and $10 \mathrm{~mm}$ or greater navicular drop for flat foot [16-18], the subjects in this study were selected based on that criterion.

According to a study conducted by Bhoir et al., $11.25 \%$ prevalence of flat foot was seen among 18-25 years old students [6], hence, the subjects selected for this study were 18-25 years old college going students.

Abtahian and Farzan in his study showed that females are more affected than males [19] and also a study was conducted by Kachoosangh et al. showed that prevalence of flat foot in girl and boy students were $75.2 \%$ and $72.6 \%$, respectively, but this study was not significant [20]. Many results have shown no significant difference according to gender [6], hence results of our study disagree with those found elsewhere. However, the reason for this may be the minimal number of male subjects in this study.

52 subjects clinically diagnosed with the flat foot and fulfilling inclusion and exclusion criteria with the age group between 18 and 25 years were included in the study. They were allocated to two groups, Groups A and $\mathrm{B}$, each containing 26 subjects. 
The baseline treatment of intrinsic muscle strengthening, i.e., toe curls, heel-raise, and short foot exercise were given to Group A and gluteal muscle strengthening exercises, i.e., clamshell, side lying hip abduction, single leg squat, and quadruped exercises along with intrinsic muscle strengthening exercises was given to Group B. The outcome was measured: Navicular drop by navicular drop test and plantar arch index by Ink test.

Baseline treatments of intrinsic muscle strengthening, i.e., toe curls, heel raise, and short foot exercises were common for both groups. Intrinsic muscle strengthening strengthens the several smaller muscles located on the bottom of the foot and helps in maintaining the near normal MLA and hence prevents the navicular drop. But as intrinsic muscle strengthening was common to both groups, the beneficial effect cannot be completely attributed to intrinsic muscle strengthening.

The average mean age of participants in Group A was $19.96 \pm 1.86$ and in Group B was $20.03 \pm 2.37$, which showed there is no significant difference in age of the subjects in both groups $\left(t_{50}=0.1299, p=0.8972\right)$. The total numbers of participants included were 52 out of which 7 were males, and 45 were females. Group A contained 2 males and 24 females whereas Group B contained 5 males and 21 females. Out of 52, 23 subjects (Group $A=11$, Group $B=12$ ) had right side flat foot, and 29 subjects (Group $A=15$, Group $B=14$ ) had left side flat foot.

Paired t-test was used to analyze the effect of intrinsic muscle strengthening on flat foot and showed that there was extremely significant improvement in the navicular drop $(\mathrm{t}=17.456, \mathrm{p}<0.0001)$ and plantar arch index $(\mathrm{t}=12.094, \mathrm{p}<0.0001)$.

Intrinsic muscle strengthening strengthens the several smaller muscles located on the bottom of the foot $[7,8]$. This helps in reducing navicular drop scores and plantar arch index scores. Reduction in both these scores helps in improving flat foot. Hence, intrinsic muscle strengthening helps in improving flat foot.

Paired t-test was used to analyze the effect of gluteal muscle strengthening on flat foot which showed that there was an extremely significant improvement in the navicular drop $(\mathrm{t}=14.738, \mathrm{p}<0.0001)$ and plantar arch index $(t=12.470, \mathrm{p}<0.0001)$.

The gluteal muscles (maximus, medius, and minimus) stabilize the hip by counteracting gravity's hip adduction torque and maintain proper leg alignment by eccentrically controlling adduction and internal rotation of the thigh $[9,10]$. Re-activating the gluteal muscles will re-establish correct muscle recruitment patterns and enhance strength and performance of gluteal muscles. Hence, gluteal muscle strengthening indirectly strengthens the kinetic chain and helps in improving flat foot.

Comparison of navicular drop between two groups was done using a unpaired $t$-test to find out the effectiveness between two groups.

The statistical analysis revealed that there was an extremely significant difference in the navicular drop in both groups. Group B was more efficient in reduction of navicular drop $(\mathrm{p}<0.0001)$ than Group A posttreatment.

Comparison of the plantar arch index between two groups was done using a unpaired t-test to find the effectiveness between two groups.

The statistical analysis revealed that there was an extremely significant difference in the plantar arch index in both groups. Group B was more efficient in reduction of the plantar arch index $(\mathrm{p}<0.0001)$ than Group A post-treatment.

The result from the statistical analysis of this study supported the alternative hypothesis which stated that there will be a beneficial effect to the subjects treated with gluteal muscle strengthening exercises along with intrinsic muscle strengthening exercises.
Hence, above result showed that subjects treated with gluteal muscle strengthening along with intrinsic muscle strengthening exercises showed better navicular drop scores and plantar arch index scores with improved flat foot.

Thus, it can be stated from the above study that gluteal muscle strengthening along with intrinsic muscle strengthening exercises are most efficacious and cost-effective.

\section{CONCLUSION}

This study concludes that there is a significant effect of gluteal muscle strengthening on the flat foot.

\section{ACKNOWLEDGMENT}

We acknowledge the guidance and constant support of Dr. G Varadharajulu, Dean, Faculty of Physiotherapy, Karad. Dr. S V Kakade for help in statistical analysis.

\section{REFERENCES}

1. Kitaoka HB, Luo ZP, An KN. Three-dimensional analysis of flatfoot deformity: Cadaver study. Foot Ankle Int 1998;19(1):447-51

2. Perrin DH. The Injured Athlete. $3^{\text {rd }}$ ed. Philadelphia, PA: LippincottRaven; 1998. p. 441-2.

3. Whitman R. A study of the weak foot with reference to its causes, its diagnosis, and its cure: With an analysis of a thousand cases of so-called flat-foot. J Bone Jt Surg Am 1896;1:42-77.

4. Neumann DA. Kinesiology of the Musculoskeletal System: Foundations for Rehabilitation. $2^{\text {nd }}$ ed. Missouri: Mosby; 2010.

5. Franco AH. Pes cavus and pes planus. Analyses and treatment. Phys Ther 1987;67(5):688-94.

6. Bhoir T, Anap DB, Diwate A. Prevalence of flat foot among 18-25 years old physiotherapy students: Cross sectional study. Indian J Basic Appl Med Res 2014;3(4):272-8.

7. McKeon PO, Hertel J, Bramble D, Davis I. The foot core system: A new paradigm for understanding intrinsic foot muscle function. Br J Sports Med 2015;49(5):290.

8. Headlee DL, Leonard JL, Hart JM, Ingersoll CD, Hertel J. Fatigue of the plantar intrinsic foot muscles increases navicular drop. J Electromyogr Kinesiol 2008;18(3):420-5.

9. Distefano LJ, Blackburn JT, Marshall SW, Padua DA. Gluteal muscle activation during common therapeutic exercises. J Orthop Sports Phys Ther 2009;39(7):532-40.

10. Moore KL, Dalley AF. Clinically Oriented Anatomy. Baltimore: Lippincott Williams \& Wilkins; 1999.

11. Patwardhan SK, Bodas KS, Gundewar SS. Coping with arthritis using safer herbal options. Int J Pharm Pharm Sci 2010;2(1):1-11.

12. Nithya S, Ray S. An experimental study on effect of granisetron on model of diabetes induced neuropathic pain perception in rats. Int $\mathrm{J}$ Pharm Pharm Sci 2014;6(1):483-6.

13. Durga GL, Jhansi CH, Ram VR, Nadendla RR. An epidemiological survey on prevalence of obesity and diseases burden in common public. Int J Pharm Pharm Sci 2014:6(2):320-2.

14. Lephart SM, Ferris CM, Riemann BL, Myers JB, Fu FH. Gender differences in strength and lower extremity kinematics during landing. Clin Orthop Relat Res 2002;401:162-9.

15. Daniel DK, Chandrasekaran C, Mano A. A study on prevalence of flat feet among school children in Kanchipuram population. Int J Anat Res 2015;3(3):1240-4

16. Lange B, Chipchase L, Evans A. The effect of low-dye taping on plantar pressures, during gait, in subjects with navicular drop exceeding $10 \mathrm{~mm}$. J Orthop Sports Phys Ther 2004;34(4):201-9.

17. Vicenzino B, Franettovich M, McPoil T, Russell T, Skardoon G. Initial effects of anti-pronation tape on the medial longitudinal arch during walking and running. Br J Sports Med 2005;39(2):939-43.

18. Tae-Ho K, Eun-Kyung K, Do-Young J. The effect of arch support taping on plantar pressure and navicular drop height in subjects with excessive pronated foot during 6 weeks. J Korean Soc Phys Med 2011;6(4):489-96

19. Abtahian A, Farzan S. A study of prevalence of flat foot in high school children. Biomed Res 2016;27(4):1295-301.

20. Kachoosangy RA, Aliabadi F, Ghorbani M. A prevalence of flat foot: Comparison between male and female primary school students. Iran Rehabil J 2013;11(18):22-4. 